\title{
RELIABILITY MODELLING OF UNINTERRUPTIBLE POWER SUPPLY USING PROBABILITY TREE METHOD
}

\author{
M.K. Rahmat ${ }^{(1)}$, S. Jovanovic ${ }^{(1)}$ and K.L. Lo ${ }^{(1)}$ \\ (1) University of Strathclyde, UK
}

\begin{abstract}
The unreliability of public power lines have led to the need of Uninterruptible Power Supply (UPS). Utility power failures will cause unacceptably high risk to the profitability, existence and growth of the vital aspect of business that depends heavily on uninterrupted power supply. For this reason it is important to develop a method to estimate the reliability of such system, to ensure that it will perform satisfactorily when needed. This paper describes and discusses an approach to predict the reliability parameters of the UPS system using the Probability Tree method. Important UPS reliability parameters such as Failure rates ( $\lambda$ ), Mean Time Between Failures (MTBF), and Reliability (R), can be obtained from this method. These quantitative reliability parameters can play an essential role in selection and application of the UPS. The method was applied to different topologies of UPS systems and comparisons were made between the results obtained form Probability Tree method and the Reliability Block Diagram (RBD) method.
\end{abstract}

\section{INTRODUCTION}

The main purpose of an Uninterruptible Power Supply (UPS) system is to protect critical electrical equipments from failures or temporary disturbances in the commercial AC power supply. Critical loads in telecommunications, information technology, financial systems, and medical treatment should not be interrupted, not even for an instant; and the UPS need to be able to supply power continuously for up to 24 hours, not only in the case of power failure but also during troubleshooting or maintenance of the system. In some unfortunate instances, the UPS failed to supply the back-up power to the critical loads when utility power fails, and consequently, the critical loads will dropped and collapsed. There are many reasons for this to happen, among others are; components or modules failure, lack of maintenance and system overload [1]. Reliability estimation was found to be one of the best methods to ensure that the UPS will be able to support the critical loads for a specified time during these unforeseen circumstances.

There are many methods being used to estimate the reliability of UPS. In the state-space method, the UPS system states are divided into operating and failed states $[2,3]$. In the first part of this method, all the system states were listed and classified as either operating or failed states. Then all the possible transitions between the different states and the causes of this transition are identified. Finally, the probabilities of being in the different states during a certain period in the life of the system were recognized. Once the steady state probabilities have been calculated, the reliability indices can be computed. In paper [3], the approach has been illustrated by developing reliability models for a standby engine generator set and an uninterruptible power supply. The works suggested that the UPS reliability indices improves considerably with increase in discharge time, and a standby generator should be considered if high reliability of critical load supply is required.

The author has also proposed the Reliability Block Diagram (RBD) method to estimate the reliability of UPS. In the RBD method, the UPS reliability model must be build first, and a failure rate, $\lambda$ (failures/hour) must be assigned to each block. The resultant reliability model is then constructed from the system's single-line diagram [4]. Major components in the UPS system were assumed to be connected either in series or parallel. Application of the RBD method in the reliability estimation of UPS systems, enables the user to obtain the system's Failure rates, MTBF and Availability. This paper will not discuss on RBD method, however, for the purpose of verification, results obtained from Probability tree method will be compared with the RBD method.

\section{MEASURES OF RELIABILITY}

In this paper, there are several reliability parameters that are useful to estimate the reliability of UPS system were determined and discussed. The proposed method enables user to achieve these parameters, and thus can be used to evaluate the reliability of the overall system. The reliability line in Figure 1 shows a graphical representation of the parameter used to determine the reliability of the system [4]. The reliability parameters that are appropriate for UPS systems are described below: 
Reliability (R): Reliability is the ability of an item to perform a required function under stated conditions for a stated period of time.

Failure rate: the mean number of system failures per unit time.

Mean Time To First Failure (MTTF or MTFF): The mean time before the occurrence of the first failure.

Mean Time Between Failures (MTBF): The expected operating time between two failures in a repairable system.

Mean Time To Repair (MTTR): The expectation of the time to restoration (or to repair).

Mean Up Time (MUT): The mean failure free time.

Mean Down Time (MDT): The mean time between the instant of failure and total restoration of the system. It includes the failure detection time, the repair time and the reset time.

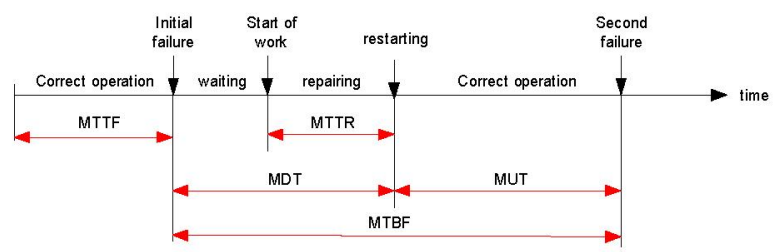

Figure 1 Reliability line

\section{PROBABILITY TREE BASIC APPROACH}

The probability tree approach involves the following steps:

1) Identify all the major components in the system which failure will leads to system failure (i.e. load collapsed).

2) Construct the reliability model for the system to show how the components/ modules are connected

3) Determine the probability of operation, $\mathrm{P}(\mathrm{OK})$ and probability of failure, $\mathrm{P}($ Fail $)$ of the component/ module from its failure rate, $(\lambda)$.

4) Identify the state of the system (i.e. system UP or system DOWN) with respect to the states of the components (i.e. component working or component fails)

Figure 2 shows probability tree of three components $\mathrm{A}, \mathrm{B}$ and $\mathrm{C}$. Outcome $\mathrm{A}$ means that component $\mathrm{A}$ is in working condition and $\hat{A}$ represents failure of component A. Following the first rule of probability, sum of $\mathrm{A}$ and $\AA$ must be equal to 1 . The same convention applies to component $\mathrm{B}$ and $\mathrm{C}$. The final result on each branch in the probability tree is the multiplication of probability from each state of its path. The summation of all the results must also equals to 1 .

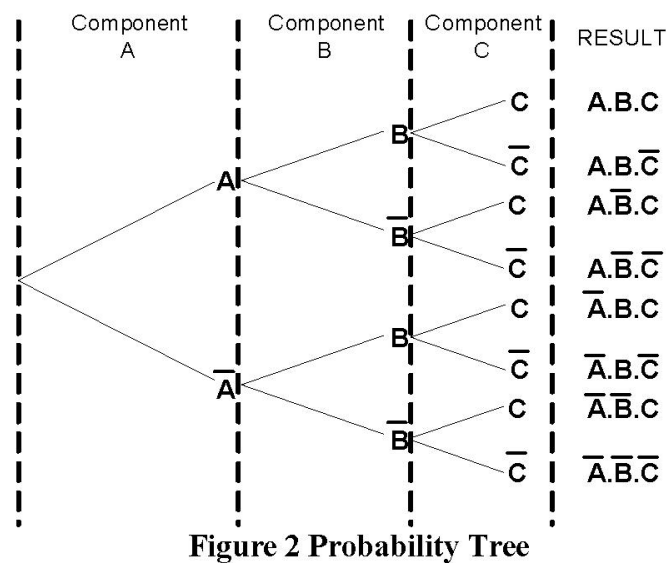

The probability trees provide an effective method in the reliability study of the UPS system because they:

1) clearly lay out the major components in the UPS system

2) allow user to analyze the possible consequences of the failure of every components

3) provides the framework to identify the final state of the system and the probabilities of achieving them.

\section{UNINTERRUPTIBLE POWER SUPPLY MODELS}

Basically, there are two types of uninterruptible power supply (UPS), namely DC UPS and AC UPS. The difference is very much dependent on the output load requirement. Figure 3 shows the single-line diagram of the two types of UPS.

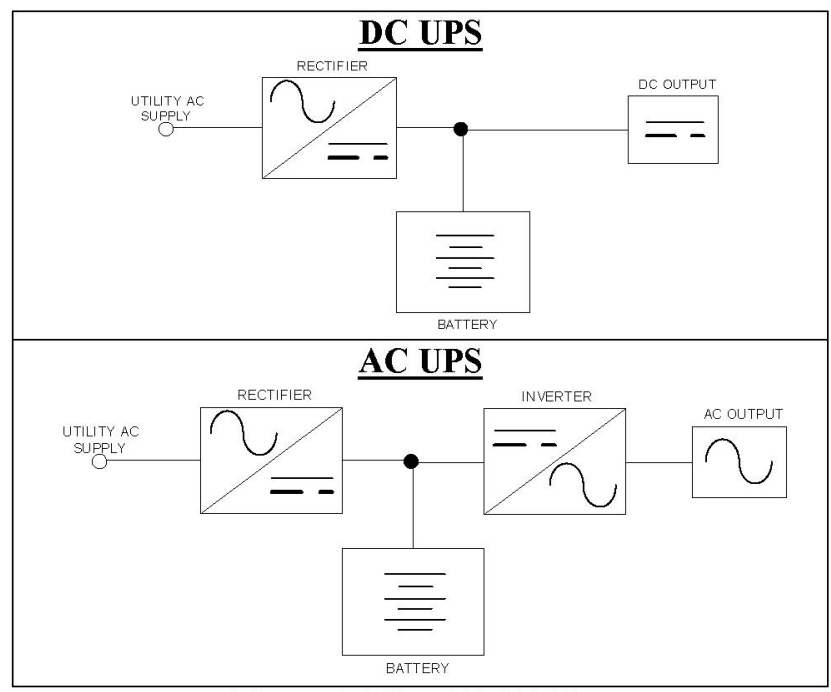

Figure $3 \mathrm{AC}$ and DC UPS

In the DC UPS, rectifier will receives ac input from utility supply and convert it to dc supply to feed the dc load and at the same time to charge the battery. During power failure, the rectifier will be off, as there will be no ac supply from utility, and thus the battery will then supply dc power to the loads. The battery back-up time will depend on state-of-charge of the battery, 
characteristic of the battery and the load level. The same working operation applies to the AC UPS, but the difference is the inclusion of inverter module that converts the dc supply (from rectifier or battery) to ac supply to feed the ac loads.

For this paper, to demonstrate the application of the probability tree method, two topologies of DC UPS were considered;

1. DC UPS with generator

2. DC UPS without generator

Figure 3 shows the reliability models for each UPS systems. Each block represents a major component in the UPS and they are either connected in series or parallel.

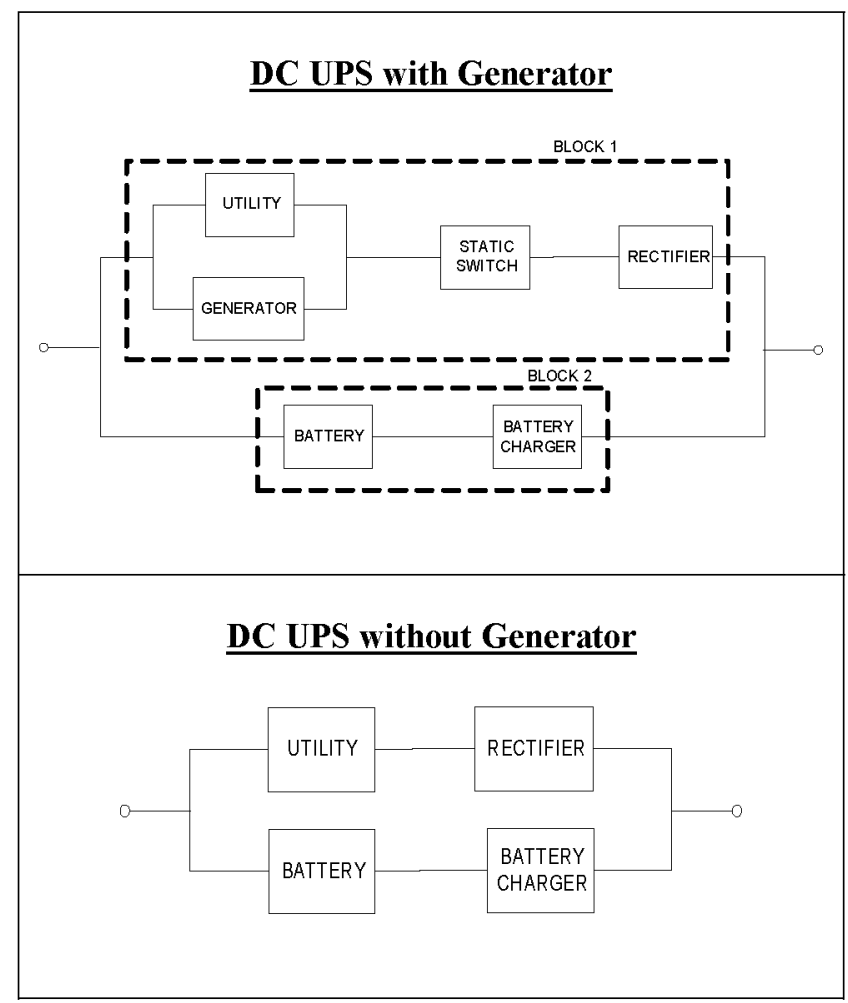

Figure 3 DC UPS Reliability Models

\section{RESULTS AND DISCUSSIONS}

The probability tree method has been applied to the two types of DC UPS to determine their reliability parameters. The failure rates $(\lambda)$ of each UPS configuration can be used to calculate the Reliability ( R) or the Probability of Operation, $\mathrm{P}(\mathrm{OK})$, of a UPS system with respect to time $(\mathrm{t})$, using the equation:

$$
\text { Re liability, } R=\exp ^{-\lambda \cdot t} \ldots\{\mathrm{Eq} 1\}
$$

In order to perform a reliability estimation using the Probability Tree method, reliability values of the components in the UPS system have to be obtained. Datasheets such as IEEE-STD-493, which provide reliability values such as the failure rates for electrical equipment based on measured field data $[5,6,7]$, were used. Table 1 shows the failure rates of the major components in the UPS systems; which can leads to probability of operation, $\mathrm{P}(\mathrm{OK})$ and probability of failure, $\mathrm{P}$ (Fail) of each components.

Table 1

\begin{tabular}{|c|c|c|c|}
\hline $\begin{array}{c}\text { UPS } \\
\text { Components }\end{array}$ & $\begin{array}{c}\text { Failure rates, } \boldsymbol{\lambda} \\
\text { (failures/ hr) }\end{array}$ & \multicolumn{2}{|c|}{$\mathbf{P}$ Y Y AR } \\
\hline Utility & $1.0000 \times 10^{-3}$ & 0.000157 & 0.999843 \\
\hline Utility/Gen & $1.5000 \times 10^{-4}$ & 0.268743 & 0.731257 \\
\hline $\begin{array}{c}\text { Bypass } \\
\text { Switch }\end{array}$ & $1.0000 \times 10^{-5}$ & 0.916127 & 0.083873 \\
\hline Rectifier & $4.3478 \times 10^{-6}$ & 0.962629 & 0.037371 \\
\hline $\begin{array}{c}\text { Battery } \\
\text { Charger }\end{array}$ & $4.3478 \times 10^{-6}$ & 0.962629 & 0.037371 \\
\hline $\begin{array}{c}\text { Batteries } \\
\text { (DC) }\end{array}$ & $1.6393 \times 10^{-7}$ & 0.998565 & 0.001435 \\
\hline
\end{tabular}

Figure 4 shows the probability tree diagram for DC UPS with generator, which consists of six major components, namely Utility, Generator, Static Switch, Rectifier, Battery and Battery Charger. The probability of operation and probability of failure of each component were used to determine the UPS total probability (i.e. state probability of the UPS). The state probability represents the power flow of the UPS system. The user will decide on the state of the UPS; whether system up or system down. "System UP" means that the UPS working satisfactorily and the critical loads are supported, while "System DOWN" means UPS failure and the critical loads are not supported (loads dropped or collapsed). The Mean Time Between Failure (MTBF) of a system can be obtained from the equation:

$$
\text { MTBF }=1 / \text { Failure Rates }
$$

\{Eq. 2\} 


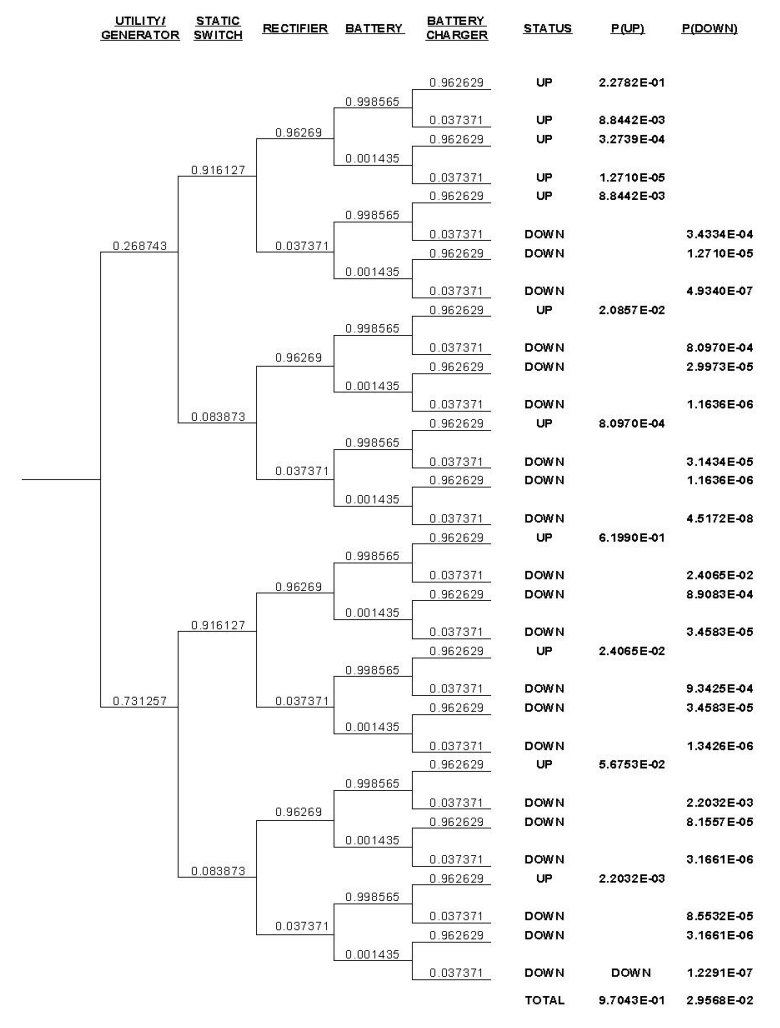

Figure 4 Probability Tree Diagram for DC UPS with Generator

\section{UPS with Generator:}

$\mathrm{P}(\mathrm{UP})=9.7043 \times 10^{-1}$

$\mathrm{P}(\mathrm{DOWN})=2.9568 \times 10^{-2}$

Failure rate, $\lambda=3.42621 \times 10^{-6}$ failures $/ \mathrm{hr}$

$\mathrm{MTBF}=291,867.960$ hours

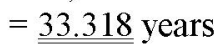

It can be seen in Figure 5 that the probability tree can be drawn for the DC UPS without generator configuration which consists of four major components (i.e. Utility, Rectifier, Battery and Battery Charger).

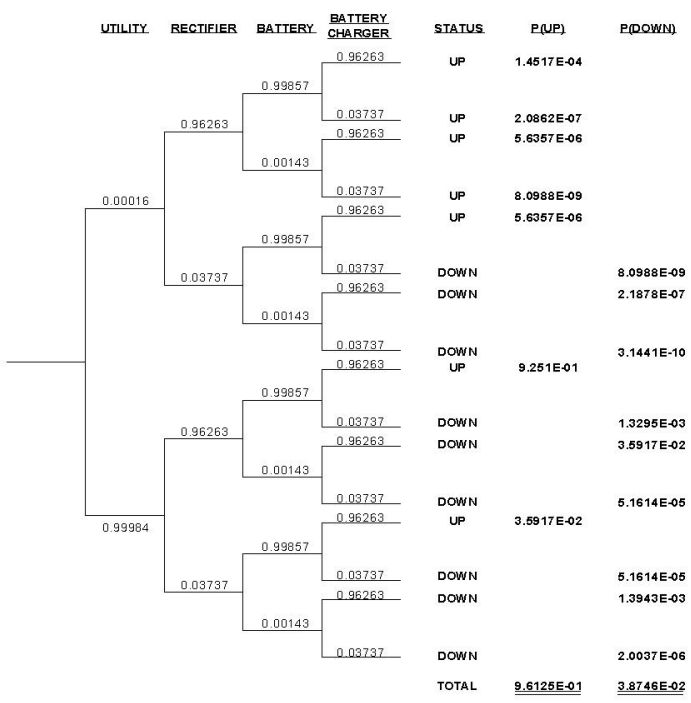

Figure 5 Probability Tree Diagram for DC UPS without Generator
DC UPS without Generator:

$\mathrm{P}(\mathrm{UP})=9.6125 \times 10^{-1}$

$\mathrm{P}(\mathrm{DOWN})=3.8746 \times 10^{-2}$

Failure rate, $\lambda=4.51103 \times 10^{-6}$ failures $/ \mathrm{hr}$

$\mathrm{MTBF}=221,678.618$ hours

$$
=\underline{25.306} \text { years }
$$

The results obtained from probability tree method for the two types of DC UPS suggested that generator can increase UPS Mean Time Between Failures (MTBF), and thus will reduce its failure rate. The generator will provide another path of the back-up power supply in the event of utility power failure. The failure rate of the generator is found to be low enough to affect the overall system failure rates.

For the DC UPS without generator, during the mains failure, the input power to the critical loads depends solely on to the battery supply and the battery supply depends on the battery's back-up time or reserve time. For the DC UPS with generator, during mains failure, the critical loads will mainly receive input supply from generator. The load will only take power from battery system during the initializing of the generator unit.

\section{PROBABILITY TREE vS. RELIABILITY BLOCK DIAGRAM}

Table 2 shows the comparisons between the results obtained from Probability Tree method and Reliability Block Diagram method. It is clearly shown that the results were very close between the two methods.

Table 2

\begin{tabular}{|c|c|c|c|c|}
\hline \multirow{2}{*}{$\begin{array}{c}\text { UPS } \\
\text { Configuration }\end{array}$} & \multicolumn{2}{|c|}{$\begin{array}{c}\text { PROBABILITY } \\
\text { TREE }\end{array}$} & \multicolumn{2}{c|}{$\begin{array}{c}\text { RELIABILITY } \\
\text { BLOCK DIAGRAM }\end{array}$} \\
\cline { 2 - 5 } & $\begin{array}{c}\text { Failur } \\
\text { Rate, } \\
\lambda\end{array}$ & $\begin{array}{c}\text { MTBF } \\
\text { (years) }\end{array}$ & $\begin{array}{c}\text { Failure } \\
\text { Rate, } \lambda\end{array}$ & $\begin{array}{c}\text { MTBF } \\
\text { (years) }\end{array}$ \\
\hline $\begin{array}{c}\text { DC UPS with } \\
\text { Generator }\end{array}$ & $\begin{array}{c}3.426 \mathrm{x} \\
10^{-6}\end{array}$ & 33.32 & $\begin{array}{c}3.607 \times \\
10^{-6}\end{array}$ & 31.65 \\
\hline $\begin{array}{c}\text { DC UPS w/out } \\
\text { Generator }\end{array}$ & $\begin{array}{c}4.512 \times \\
10^{-6}\end{array}$ & 25.31 & $\begin{array}{c}4.492 \times \\
10^{-6}\end{array}$ & 25.42 \\
\hline
\end{tabular}

Table 3 shows the advantages and disadvantages of both methods. Although the Probability tree is a faster method to achieve reliability parameter, (as less calculations needed) compared to RBD method; it was found to be unpractical for a large system with more redundancies in the system. The reason is because in a larger system, there will be more components and system states to be considered. Although this problem can be solved by a lengthy computer programming, $\mathrm{RBD}$ is found to be a more preferred method for larger systems.

In Probability tree method, all system states (system UP and DOWN) were considered, unlike in RBD where 
only the failure states (i.e. component's failure rates) were used. The mathematical model in RBD method enables users to perform sensitivity analysis quite easily, by varying the failure rates of the components to investigate its effect on the overall system's reliability.

Table 3

\begin{tabular}{|c|c|}
\hline \multicolumn{2}{|c|}{ PROBABILITY TREE } \\
\hline $\begin{array}{l}\text { - Fdvantages } \\
\text { - Fast method } \\
\text { - Less calculations } \\
\text { - All system states are } \\
\text { considered }\end{array}$ & $\begin{array}{l}\text { Disadvantages } \\
\text { oUser decides system } \\
\text { states (UP/DOWN) } \\
\text { o Unpractical for large } \\
\text { system with more } \\
\text { redundancies }\end{array}$ \\
\hline \multicolumn{2}{|c|}{ RELIABILITY BLOCK DIA GRAM } \\
\hline $\begin{array}{l}\text { Advantages } \\
\text { - Can perform sensitivity } \\
\text { analysis easily } \\
\text { - More practical for large } \\
\text { system }\end{array}$ & $\begin{array}{l}\text { Disadvantages } \\
\text { o More calculations - } \\
\text { series/parallel blocks } \\
\text { Only consider system } \\
\text { Fail state }\end{array}$ \\
\hline
\end{tabular}

There is a similarity between the two methods; as both methods require the system's reliability model to be constructed first to show how the components/modules are connected.

\section{CONCLUSIONS}

In this paper, we suggest a new method of estimating the reliability parameters (failure rates and MTBF) of the Uninterruptible Power Supply (UPS) system by using probability tree. Reliability estimation of the UPS plays a very important role in the design, planning and operation stages of a system, in order to minimise the risk of not having a required back-up power when needed, produce mainly by component failures and consequently leads to interruption to the critical loads.

The results from this paper suggested that in order to increase the reliability of UPS system to cater for critical loads, a generator must be used. Inclusion of the generator into the system will increase the overall system's MTBF and thus will reduce the failure rates.

From the comparison between Probability tree and RBD method, the following points can be drawn:

- The result obtained from both methods are nearly equal

- Both techniques require system's reliability model to be constructed first

- Probability tree technique is able to provide faster and simpler reliability estimation

- RBD method is more practical for a larger system.

\section{REFERENCES}

1. IEEE Std. 446-1995, 'Recommended Practice for Emergency and Standby Power Systems for Industrial and Commercial Applications - IEEE Orange Book'

2. C. Singh, N. Gubbala, N. Gubbala, "Reliability Analysis of Electric Supply Including Standby Generators and an Uninterruptible Power Supply System", IEEE Transaction of Industry Applications, Vol.30, No.5 Sept/Oct 1994

3. C. Singh, A. Patton, "Reliability Evaluation of Emergency and Standby Power Systems", IEEE Transaction of Industry Applications, Vol.21, No.2 Mar/Apr 1985

4. A. Villemeur, "Reliability, Availability, Maintainability and Safety Assessment: Volume 1", John Wiley and Sons, 2000.

5. S. Roy, "Reliability Consideration for Data Centres Power Architectures", IEEE International Telecommunications Energy Conference, INTELEC 1997, Melbourne, Australia.

6. J. Akerlund, "DC Computer Equipment Technologyan Emerging Technology", IEEE International Telecommunications Energy Conference, INTELEC 1998, San Francisco, USA.

7. MIL-HDBK-338B: Military Handbook: Electronic Reliability Design Handbook, October 1998.

\section{AUTHOR'S ADDRESS}

The first author can be contacted at:

Power System Research Group

Dept. of Electronic and Electrical Engineering

University of Strathclyde

204 George Street

Glasgow, G11XW

Scotland, UK

email: mohd.k.rahmat a,strath.ac.uk 